\title{
LAS RELACIONES JURÍDICAS
}

1. Examen de algunas doctrinas sobre el concepto de relación juridica

1. Según Francesco Bernardino Cicala, quien ha consagrado un extenso libro al estudio del concepto a que este artículo se refiere, ${ }^{1}$

lo stato della dottrina, nostrana e straniera, mostra che le teorie sul "rapporto giuridico". siano tanto scarse e monche, quanto varie ed esaurienti sono state al contrario quelle sul "negozio giuridico", tema favorito degli scrittori giuridici moderni. ${ }^{2}$

Después de examinar, en actitud crítica, las definiciones propuestas por Savigny, Windscheid, Oertmann, Puchta, Neuner, Bierling, Voigt, Puntschart, Jhering y otros, Cicala resume así su objeción principal a tales autores: todos ellos - dice- se obstinan en considerar la relación jurídica como un vínculo entre el sujeto de un derecho y el mundo exterior, personas o cosas; pero ignoran

una relazione ideale, necessaria e sufficiente per l'esistenza di ogni rapporto giuridico: quella cioè tra il soggetto e l'ordinamento giuridico. ${ }^{3}$

Todas las veces que, voluntariamente o no, el individuo se halla en alguna de las situaciones previstas por aquel ordenamiento, surgirá una relación jurídica,

un rapporto ciò̀ tra l'individuo (termine soggettivo, o soggetto) e le norme giuridiche (termine oggettivo, od oggetto del rapporto medesimo) applicabili alla rispettiva fattispecie. ${ }^{4}$

Si es verdad que las relaciones morales son los vínculos entre el individuo y la ley moral, y las religiosas las que existen entre el individuo y los preceptos de su credo religioso, ¿por qué no admitir, del mismo modo, una relación ideal semejante entre el hombre y las normas del orden jurídico a él aplicables? 5

No hay duda de que la sociedad humana es un presupuesto indispensable del orden jurídico, porque, sin la coexistencia de sus componentes no es 1959.

1 Il rapporto giuridico, Milano, Dott. A. Giuffrè Editore, Quarta edizione riveduta,

2 Ibid., p. 3 .

3 Ibid., p. 17.

4 lbid., p. 18.

5 Ibid., p. 19 . 
posible que surjan ni la idea del derecho ni la de la justicia. Frente a dicha sociedad, nuestro pensamiento

è spinto irresistibilmente, dalla propria stessa essenza, a porre un "rapporto" tra ciascuno dei consociati e le norme a ciascuno rispettivamente aplicabili.

Pero, al lado del vínculo entre el sujeto y las normas del derecho objetivo, el pensamiento humano descubre otro, ya no como "esencia" de la relación, sino como efecto suyo en la sociedad: el que media entre el mismo sujeto y todos los coasociados en general. Para Cicala, el contenido necesario de toda relación jurídica es el derecho subjetivo, y éste consiste en un poder del sujeto frente a la comunidad jurídica.

Ma tale relazione generale, cui dà origine ogni rapporto giuridico, deve andare ben distinta da quella relazione speciale tra persona e persona, dal carattere economico-sociale, che, secondo tutte le teorie esistenti, da me respinte, costituirebbe l'essenza dei rapporti giuridici. ${ }^{6}$

La doctrina expuesta tiene el mérito indudable, frente a las concepciones tradicionales, de subrayar la necesidad de que el punto de partida de la teoría de la relación jurídica se haga consistir en los vínculos entre las normas de cada sistema y los sujetos a quienes, cuando determinados supuestos se han cumplido, tales normas son aplicables. Pues lo que de jurídico hay en esos vínculos es, precisamente, el hecho de que tienen su fundamento en el susodicho sistema. Hay, sin embargo, algunos aspectos del pensamiento de Cicala con los que no podemos estar de acuerdo. Nos parece criticable, ante todo, la afirmación de que a las normas, como término de una relación entre el sujeto y el orden jurídico, debe dárseles el nombre de "objeto" del mismo vínculo. Lo que movió a Cicala a usar tal término fue, sin duda alguna, la circunstancia de que los autores suelen contraponer al derecho como facultad, o derecho subjetivo, el derecho como conjunto de normas, o derecho objetivo. Pero que, frente a las personas (colectivas o individuales) las normas de su sistema aparezcan como algo "objetivo", no justifica la aplicación de la palabra "objeto" a lo que en realidad constituye el fundamento del nexo entre esas personas y los preceptos reguladores de su conducta. No es lo mismo, en efecto, llamar "objetivo" a uno de los términos de tal vínculo, que decir que constituye el "objeto" de éste. Si por "objeto" de un derecho subjetivo o de un deber jurídico se entiende, ya la conducta que el titular del derecho puede observar licitamente, ya -en el caso del deber- lo que el obligado debe hacer u omitir, y las relaciones juridicas interpersonales - por cierto no las únicas- suponen siempre la existencia de facultades y deberes recíprocos, no hay duda de que, al menos tratándose

6 Ibid., p. 21. 
de aquéllas, lo correcto es llamar "objeto" al contenido de las mismas y no a uno de sus términos. Para convencerse de lo anterior basta con reflexionar en que la forma o estructura de una norma, una relación jurídica, una obligación o un derecho subjetivo son siempre -como dice Somló- el elemento constante de todos ellos, ${ }^{7}$ en tanto que el contenido -o materiarepresenta, por el contrario, el elemento variable e individualizante de cada uno. ${ }^{8}$ No hay, pues, ninguna razón que impida dar también el nombre de "objeto" al contenido de las relaciones que median entre las normas de un sistema y los sujetos a quienes, en tales o cuales circunstancias, esas normas deben aplicarse, sobre todo si se recuerda que el elemento distintivo o individualizador de los vínculos de la indicada especie es el de orden material o, en otras palabras, su "objeto".

La distinción entre elemento formal y elemento material de las relaciones de derecho es muy clara, por ejemplo, en Savigny. Refiriéndose a este punto, el famoso jurista escribe:

Es erscheint uns jedes einzelne Rechtsverhältnis als eine Beziehung zwischen Person und Person durch eine Rechtsregel bestimmt... daher lassen sich in jedem Rechtsverhältnis zwei Stücke unterscheiden, 1. ein Stoff, das heisst jene Beziehung an sich, 2. die rechtliche Bestimmung dieses Stoffes. Das erste Stück können wir als das materiale Element oder als die blosse Tatsache in demselben bezeichnen, das zweite als ihr formales Element, das heisst dasjenige, wodurch die Tatsachenbeziehung zur Rechtsform erhoben wird.9

Lo que Cicala censura a Savigny, como a muchos otros autores, es la limitación del concepto de relación jurídica al caso de la existente entre persona y persona. Es justo reconocer, sin embargo, que aun cuando el jurista alemán no se refiera expresamente a las relaciones entre normas y sujetos, implícitamente admite que existen, en la medida en que afirma que lo que determina la índole jurídica del vínculo interpersonal es la norma o el conjunto de normas reguladoras de éste.

Debe advertirse, además, que no sólo existen relaciones entre normas y personas, sino también -y necesariamente- entre normas y hechos jurídicos. Pues, como Cicala lo reconoce, las del primer grupo presuponen que determinados supuestos normativos se han realizado o, lo que es igual, que hay un vínculo entre éstos y los hechos que los realizan.

Hemos visto cómo, de acuerdo con la doctrina que estamos discutiendo, al lado del nexo entre el sujeto y las normas del derecho objetivo, el pensa-

7 F. Somló, Juristische Grundlehre, Zweite Aufl., Verlag Felix Meiner, Leipzig, 1927, Einleitung.

8 Cf. E. García Máynez, Lógica del concepto juridico, Fondo de Cultura Económica, México, 1959, cap. III, 1.

9 Savigny, System, I. S. 331, 55. 
miento humano descubre otro, ya no como "esencia" de la relación, sino como efecto suyo en la sociedad: el que media entre el mismo sujeto y todos los coasociados en general.

Si, a consecuencia de la realización del supuesto de una norma -en el caso de un contrato de mutuo, verbigracia - surge un vínculo entre acreedor y deudor y, consecuentemente, el primero de estos sujetos adquiere el derecho de exigir del segundo (cuando el término se venza) la devolución de lo que le prestó, el "efecto" del nexo existente entre el derecho objetivo y el sujeto facultado es, según el tratadista italiano, una nueva relación: la que media entre tal sujeto y la comunidad. Pero el sujeto pasivo de dicha relación no es ni puede ser la comunidad juridica como ente abstracto o sujeto unitario; por ende, resulta incorrecto decir, como lo hace Cicala, que el derecho subjetivo -en el caso de nuestro ejemplo la facultad jurídica del acreedor - es un poder de éste "frente" a la comunidad. El derecho subjetivo a la devolución de lo prestado no lo tiene el mutuante respecto de aquélla, sino -exclusivamente- frente a su deudor. Éste, en efecto, es el pasible del deber correlativo del derecho de la otra parte. Pero como la facultad jurídica del acreedor no es de ejercicio obligatorio, puesto que no se funda en un deber del mismo sujeto, el último tiene, además de su derecho de crédito, un derecho absoluto de libertad, en ejercicio del cual puede lícitamente optar entre exigir y no exigir la devolución de la suma prestada. El segundo derecho, por su mismo carácter absoluto, existe erga omnes, y el deber correlativo es el impuesto a los demás, frente al titular de la facultad fundante, de no impedirle que ejercite su derecho de crédito - si quiere ejercitarlo- ni exigirle que lo ejercite — si no quiere hacer uso de él. El susodicho deber de respeto -en cualquiera de sus dos formas de manifestación- no es un deber de la comunidad, unitariamente considerada, sino de todos los miembros de ésta frente al acreedor. Conviene, pues, distinguir con pulcritud la relación juridica de crédito -existente entre el mutuante y el mutuatario- de la relación juridica de libertad. En la primera, al derecho subjetivo del acreedor corresponde una obligación especial del deudor: devolver la suma prestada; en la segunda, al derecho de libertad del primero de los dos sujetos corresponde el deber, impuesto a todos los demás, de respetar las dos posibles manifestaciones de su libertad jurídica, esto es, ya la voluntad de ejercitar, ya la de no ejercitar el derecho de crédito. ${ }^{10}$

La "relación general" que Cicala cree descubrir entre el sujeto facultado y el orden jurídico debe ser, según el mismo autor, claramente distinguida

da quella relazione speciale tra persona e persona, dal carattere economico-sociale, che, secondo tutte le teorie esistenti, da me respinte, costituirebbe l'essenza dei rapporti giuridici.

10 Cf. E. García Máynez, Introducción a la lógica juridica, Fondo de Cultura Económica, México, 1951, cap. VI, 4־5. 
Aun cuando no puede negarse que la relación intersubjetiva tiene muchas veces un contenido o, como preferimos decir, una infraestructura económicosocial, ello no le quita su carácter jurídico, puesto que se trata de un nexo entre sujetos de derecho, de los cuales uno figura como titular de una facultad normativa y el otro como pasible de un deber. Las normas legales poseen otras veces una infraestructura de carácter biológico, cual ocurre en el caso de las que regulan relaciones entre padres e hijos; pero la naturaleza de aquélla tampoco priva a dichos nexos de su índole jurídica.

II. Es muy frecuente -escribe Fritz Schreier- que las relaciones juridicas sean confundidas con sus términos. Por eso algunos dan ese nombre a los hechos condicionantes, y otros a las consecuencias de derecho.

Según Bekker, el giro "relación jurídica" es empleado para designar:

a) ein Verhalten, an welches das objektive Recht Rechtsfolgen knüpft und b) eben die angeknüpften Folgen". ${ }^{11}$ Wir brauchen wohl nicht erst ausdrücklich darauf hinweisen -comenta Schreier- dass Rechtsverhältniss nicht das Verknüpfte, sondern die Verknüpfung selbst ist, also die Relation. ${ }^{12}$

Hay, pues, que partir - según el jurista austríaco- de la norma de derecho, no de algo que está más allá de ella.

Der Fehler der heutigen Jurisprudenz steckt darin, dass sie gegen diesen Prinzip verstösst. Rechtsvoraussetzung und Rechtsfolge werden von ihr nicht als relative, sondern als absolute Begriffe angesehen. ${ }^{13}$

Nada tiene entonces de extraño que en el lugar de la unidad formal de la relación normativa se coloque la material de una "relación de vida".

Das Recht tritt dann zu diesen, bereits vorhandenen Lebensverhältnissen hinzu, sie anerkennend und bestätigend oder verwerfend, ohne dass jedoch hiedurch eine wesentliche Veränderung in den "Lebensverhältnissen" selbst vor sich geht. Selbstredend wird hiedurch der Weg zur Erkenntnis der Eigengesetzlichkeit des Rechts endgültig verbaut. So kommt es zu Definitionen wie: "Rechtsverhältnis ist ein vom objektiven Recht anerkanntes Lebensverhältnis" (Regelsberger, Pandekten, SS. 71); "Rechtsverhältnis ist eine rechtlich wirksame Beziehung einer Person zu einer anderen Person oder zu Sachgütern... Rechtsinstitute sind rechtlich geregelte Einrichtungen der bürgerlichen Gesellschaft" (Dernburg, Pandekten, 40); "Der Inbegriff der Rechtsbeziehungen, die einem bestimmten Lebensverhältnis entsprechen, ist ein Rechtsverhältnis" (Gierke, Deutsches Privatrecht, 55$).^{\mathbf{1 4}}$

11 Bekker, Pandekten, 17. Cita de Schreier en la p. 106 de Grundbegriffe und Grundformen des Rechts, Franz Deuticke Verlag, Leipzig und Wien, 1924.

12 Schreiex, op. cit., p. 106.

13 Ibid.

14 lbid. 
Schreier afirma que el primero que frente a estos errores metodológicos señaló el camino recto, fue Töhl. Su punto de partida es, también, inexacto, pues al plantearse el problema definitorio escribe lo siguiente:

Ein Verhältnis ist ein Tatbestand... und wenn es ein Recht begründet, ein Rechtsverhältnis. ${ }^{1 \bar{a}}$

Pero su mérito consiste en que concibe esta relación como fundada en la norma de derecho. Por ello combate la tesis de Puchta, según la cual el derecho se compone de instituciones, las cuales se componen, a su vez, de normas de derecho. Según Töhl, más bien habría que decir:

Das Recht besteht aus Rechtssätzen, diese begründen Rechtsinstitute. ${ }^{16}$

\section{Distinción entre relación juridica vertical y relación juridica horizontal}

Si reconocemos que el fundamento de toda relación jurídica reside en el derecho objetivo y al mismo tiempo aceptamos que el vínculo entre pretensor y obligado es también jurídico, y no, como asevera Cicala, una simple relación social o económica, podremos, para distinguir los dos casos, hablar de relaciones jurídicas verticales y horizontales.

Para la inteligencia de tal distinción ejemplificaremos con la norma según la cual "si un trabajador sufre un accidente de trabajo, el trabajador tiene el derecho de exigir el pago de una indemnización al patrono". El análisis de tal norma, lo mismo que el de la correspondiente prescriptiva: "si un trabajador sufre un accidente de trabajo, el patrono tiene el deber de pagar una indemnización al obrero", revelan que cada una de ellas se compone de un supuesto y una disposición, y que la parte dispositiva de las mismas encierra tres elementos lógicos: el concepto-sujeto, 2) la cópula juridica; 3) el predicado relacional.

Tanto las nociones de supuesto y disposición, como las de sujeto, cópula y predicado relacional, asumen, según lo hemos explicado en diversos trabajos, carácter lógico-juridico, y a ellas corresponden, én el plano de la conducta jurídicamente regulada; $\mathrm{u}$ ontológico-juridico, los conceptos de hecho juridico, consecuencias de derecho, pretensor y obligado, derecho subjetivo y deber juridico, objeto del derecho y objeto del deber.

$\mathrm{Si}$ primeramente consideramos la correlación supuesto juridico-hecho juridico, sin perder de vista nuestro ejemplo, advertiremos que al supuesto de ambas normas, la atributiva y la prescriptiva, corresponde en el plano

15 Einleitung in das Deutsche Privatrecht, 41 , p. 114. Cita de Schreier en la p. 108 de su obra.

16 Cita de Schreier. 
ontológico, cuando éstas son aplicadas, un hecho juridico: el accidente que un obrero sufre al servicio de tal o cual patrón.

El hecho con que estamos ejemplificando es jurídico en cuanto realiza el supuesto de aquellas normas. Al afirmar tal cosa establecemos una relación entre dos planos distintos: el lógico-jurídico y el ontológico-jurídico. Pero como el primero es determinante del otro, parece adecuado dar el calificativo de verticales a las relaciones entre ambos.

Refirámonos ahora a las que existen entre los elementos de la disposición normativa y los correspondientes conceptos ontológico-jurídicos, utilizando, para explicarlas, eI siguiente cuadro:

\begin{tabular}{|c|c|c|c|c|}
\hline Concepto sujeto & Cópula juridica & \multicolumn{3}{|c|}{ Predicado relacional } \\
\hline \multirow{2}{*}{$\begin{array}{l}\text { "El obrero que ha } \\
\text { sufrido un acciden- } \\
\text { te de trabajo }\end{array}$} & tiene el derecho de & exigir & $\begin{array}{l}\text { el pago de una in- } \\
\text { demnización }\end{array}$ & al patrono". \\
\hline & & 1. & 2. & 3. \\
\hline $\begin{array}{l}\text { Concepto determi- } \\
\text { nante del sujeto del } \\
\text { derecho. }\end{array}$ & $\begin{array}{l}\text { Concepto determi- } \\
\text { nante de la fun- } \\
\text { ción del sujeto en } \\
\text { la rel. jurídica. }\end{array}$ & \multicolumn{3}{|c|}{$\begin{array}{l}\text { Conceptos parciales determinantes del objeto del } \\
\text { derecho y del sujeto del deber correlativo. }\end{array}$} \\
\hline \multirow[t]{2}{*}{ "El patrono } & tiene el deber de & pagar & una indemnización & $\begin{array}{l}\text { al obrero que ha } \\
\text { sufrido un acci- } \\
\text { dente de trabajo". }\end{array}$ \\
\hline & & 1. & s. & 3. \\
\hline $\begin{array}{l}\text { Concepto determi- } \\
\text { nante del sujeto del } \\
\text { deber juridico. }\end{array}$ & $\begin{array}{l}\text { Concepto determi- } \\
\text { nante de la fun- } \\
\text { ción del sujeto en } \\
\text { la rel. jurídica. }\end{array}$ & \multicolumn{3}{|c|}{$\begin{array}{l}\text { Conceptos parciales determinantes del objeto del } \\
\text { deber y del sujeto del derecho correlativo. }\end{array}$} \\
\hline
\end{tabular}

Para poder afirmar válidamente que (de acuerdo con tales o cuales normas), si un trabajador ha sufrido un accidente de trabajo al servicio de un patrono, la víctima del accidente tiene el derecho de exigir el pago de una indemnización, es necesario haber establecido antes: 1) que entre el sujeto $x$ y el sujeto $y$ existe la relación de trabajo; 2) que el sujeto $x$ sufrió un accidente; 3) que el accidente sufrido por $x$ es (de acuerdo también con tales o cuales normas) un accidente de trabajo; 4) que el sujeto $x$ sufrió el accidente al servicio del patrono $y$. Obsérvese que tanto el juicio 'entre el sujeto $x$ 'y el sujeto $y$ existe un contrato de trabajo' como los juicios ' $x$ sufrió un accidente de trabajo al servicio del patrono $y$ ' y ' $x$ tiene el derecho de exigir de $y$ una indemnización por el accidente que sufrió a su servicio', son todos juicios relacionales.

Cuando decimos que un hecho jurídico (en el caso del ejemplo: un 
accidente) realiza el supuesto de la norma aplicable, lo que queremos expre. sar, desde el punto de vista lógico, es que tal hecho pertenece a la clase de los accidentes de trabajo. Lo que determina su pertenencia a la indicada clase o, en otras palabras: lo que permite afirmar de un hecho $h$ que es un accidente de trabajo, es la concurrencia, en el mismo, de las notas definitorias de todo accidente de tal clase. Para subsumir el hecho $h$ bajo el correspondiente supuesto legal es, pues, indispensable haber establecido previamente la indicada relación de pertenencia o, en otras palabras, haber aplicado a tal hecho una norma distinta, conviene a saber, la que obliga a considerar como accidente de trabajo todo hecho en el cual concurran las notas que señala la definición legal del mismo concepto. Por ello podemos sostener que esa definición determina el carácter jurídico de $h$, y que entre la norma de que la definición forma parte y $h$ existe una relación jurídica vertical.

Del mismo tipo son las existentes entre la norma que impone el deber de considerar como trabajador a todo sujeto en quien concurran las notas definitorias del concepto 'trabajador' y un sujeto $x$; o entre la norma que impone el deber de considerar como patrono a todo sujeto en quien concurran las notas definitorias del concepto 'patrono' y un sujeto $y$. Pues en todos estos casos dichas normas determinan qué propiedades condicionan la pertenencia de un objeto a una clase.

Si ahora volvemos al precepto que nos sirvió como punto de partida, es decir, al que establece que si un trabajador ha sufrido un accidente tiene el derecho de exigir de su patrono el pago de una indemnización, y examinamos su parte dispositiva, podremos afirmar, como lo indica el cuadro, que las palabras "el obrero que ha sufrido un accidente de trabajo" determinan, cuando la correspondiente norma es aplicada, al sujeto del derecho, esto es, al facultado para exigir del patrono el pago de la indemnización. Tal sujeto puede ser individualizado no en cuanto forma parte de la clase trabajador, ni de la subclase de ésta designada por las palabras "trabajador que ha sufrido un accidente de trabajo", sino en cuanto es la víctima del ocurrido en tal o cual fecha, al servicio de tal o cual patrono, y del que resultó para el asalariado tal o cual incapacidad. La determinación de que el accidente sufrido en esa fecha por $x$ es de trabajo, está condicionada por una doble pertenencia: a) la de $x$ a la clase de los trabajadores; b) la del mismo $x$ a la clase de los que han sufrido un accidente de trabajo. La primera de las dos está condicionada por el contrato laboral de $x$ con $y$; la segunda, por el accidente sufrido por $x$ al servicio de $y$. Ambas tienen su fundamento en el derecho objetivo; ambas, también, vinculan el plano de la regulación juridica de la conducta con el de la conducta juridicamente regulada $\mathrm{y}$, por ende, son relaciones de carácter vertical.

Pero la aplicación de la norma genérica al caso concreto, es decir, al accidente de trabajo sufrido por $x$-aplicación que supone y exige la de 
otras normas conexas - no sólo determina la índole jurídica de $h$, esto es, su carácter de accidente de trabajo, sino que le imprime el de condicionante de las consecuencias de derecho. Esta relación es distinta de las anteriormente examinadas, es decir, de la de pertenencia de $x$ a la clase de los trabajadores; de la de pertenencia de $h$ a la clase de los accidentes de trabajo y de la de pertenencia de $x$ a la clase de los trabajadores que han sufrido un accidente de trabajo. Las tres a que acabamos de referirnos son relaciones verticales; la que existe entre el hecho condicionante y las consecuencias de derecho es, en cambio, una relación jurídica horizontal. Pues aun cuando esté condicionada por una relación vertical, a saber: la de pertenencia de $h$ a la clase de los accidentes de trabajo, sus términos no aparecen en dos planos distintos, el lógico-jurídico y el ontológico-jurídico, sino exclusivamente en el segundo. En cuanto $h$ realiza el supuesto de la norma genérica, ésta le es aplicable; en cuanto le es aplicada, su aplicación condiciona el nacimiento del derecho subjetivo de $x$ frente al patrón.

En el plano ontológico-jurídico debemos, pues, distinguir, sin olvidar nuestro ejemplo, 1) la relación entre el condicionante y su consecuencia; 2) la interpersonal de $x$ con $y$. Ambas son, como es obvio, relaciones jurídicas horizontales.

Lo que hemos afirmado en conexión con la norma atributiva del derecho, podemos también decirlo de la impositiva del deber. Las dos tienen el mismo supuesto (es decir, el de que un obrero sufra un accidente de trabajo); pero sus disposiciones son distintas, pues en tanto que la primera atribuye al trabajador un derecho subjetivo, la segunda impone un deber jurídico al patrono. Cabe, sin embargo, considerarlas como equivalentes (en sentido lógico), pues, aun cuando la significación de las oraciones que las expresan sea diferente, una de ellas está referida al aspecto activo y la otra al aspecto pasivo de un mismo vínculo: el interpersonal entre patrono y trabajador. En el caso de la norma prescriptiva habrá, pues, que distinguir también: 1) la relación de pertenencia del hecho jurídico $h$ a la clase de los accidentes de trabajo; 2) la de pertenencia de y a la clase de los patronos, y 3) la de pertenencia de $y$ a la clase de los patronos de un trabajador que ha sufrido un accidente de trabajo. Esta última distinción es necesaria, porque el deber de $y$ de pagar a $x$ una indemnización, no la tiene $y$ simplemente en cuanto patrono, sino en cuanto patrono de un obrero que ha sido víctima de un accidente. Las tres relaciones son de tipo vertical, ya que vinculan el plano de la regulación jurídica de la conducta con el de la conducta jurídicamente regulada. La que media entre el hecho condicionante y el deber de $y$ frente. a $x$ es, en cambio, horizontal, pues aun cuando está condicionada por la de pertenencia de $h$ a la clase de los accidentes de trabajo, sus términos aparecen exclusivamente en el plano ontológico-jurídico. 


\section{Análisis de la relación juridica interpersonal}

La disposición de cada una de las dos normas, la atributiva y la prescriptiva, consta de tres conceptos: 1) el concepto-sujeto; 2) la cópula; 3) el predicado relacional. Volviendo a nuestro ejemplo podemos decir que el primero de los tres, expresado por las palabras: "El obrero que ha sufrido un accidente de trabajo", es determinante del sujeto del derecho; el segundo: "tiene el derecho", determina la función del mismo sujeto en la relación interpersonal, es decir, su carácter de pretensor; el tercero: "exigir el pago de una indemnización al patrono", está integrado, como el cuadro lo indica, por tres nociones parciales: 1) "exigir"; 2) "el pago de una indemnización"; 3) "al patrono". Estas nociones parciales son determinantes: a) del objeto del derecho; b) del sujeto del deber correlativo. Según lo hemos explicado en nuestra Lógeca del concepto juridico, en cada uno de los mencionados conceptos parciales de la disposición atributiva hay una referencia a los de la disposición prescriptiva que impone al patrono el deber de indemnizar a la víctima del accidente. En el concepto "obrero" está implicada la. referencia al correlativo "patrono"; en la cópula "tiene el derecho de", la referencia al correlativo "tiene el deber de" y, en el predicado relacional, la referencia al objeto del deber y al sujeto de la obligación correlativa.

De los conceptos parciales que forman el predicado relacional de la norma atributiva, "exigir" determina, según dijimos antes, el objeto del derecho a que hace referencia la cópula del juicio o, en otras palabras, indica que el obrero tiene, frente al patrono, una facultas exigendi, esto es, el derecho de reclamar algo de él. El segundo de esos conceptos parciales, o sea, "el pago de una indemnización", precisa lo que, en ejercicio de aquella facultad, el trabajador puede exigir, esto es, el pago de una indemnización. Por último, el expresado por las palabras "al patrono", determina a todos los anteriores, en cuanto dice a quién puede el obrero exigir que se le indemnice.

Para aplicar la norma genérica: "El obrero que sufre un accidente de trabajo tiene el derecho de exigir el pago de una indemnización al patrono", no basta con subsumir el hecho condicionante bajo la hipótesis normativa; es necesario, además, individualizar la consecuencia legal. Los criterios de acuerdo con los cuales tal individualización debe hacerse los ofrece, en cada caso, el derecho positivo. Supongamos, para continuar con nuestro ejemplo, que, como resultado del accidente de trabajo, $x$ pierde una pierna, y que la ley aplicable impone al patrono el deber de pagar, por concepto de indemnización, una cantidad equivalente al importe de trescientos días de salario. De este modo, como diría Engisch, ${ }^{17}$ todos los casos en que el resultado de un accidente es la pérdida de una pierna, son "subordinados" al supuesto de la

17 Cf. Karl Engisch, Logische Studien zur Gesetzesanwendung, Zweite Aufl., Carl WinterUniversitätsverlag, Heidelberg, 1960, p. 17. 
norma que impone al patrono el deber de indemnizar. Desde el punto de vista lógico ello equivale, en situaciones como la del ejemplo, a la definición de una ciase especial de accidentes de trabajo. Cuando el sufrido por la víctima pertenece a esta clase especial, otra norma del sistema indica cómo debe calcularse el monto de la indemnización. Para individualizar la consecuencia de derecho es, pues, indispensable establecer una doble relación de pertenencia: a) la del accidente sufrido por $x$ a la mencionada clase especial; b) la de la indemnización que $y$ debe pagar a $x$ a la clase de las que equivalen al importe de trescientos días de salario. La individualización de las consecuencias normativas no se hace siempre del mismo modo. La del castigo que debe imponerse a un delincuente, en sistemas que admiten el llamado arbitrio judicial, por ejemplo, puede hacerse de acuerdo con los criterios que ofrece el código de la materia, y que no se refieren a notas definitorias del hecho delictuoso, sino a otras peculiaridades -antecedentes del autor del delito, ejempligracia- que el juez debe ponderar a la luz de aquellos criterios, en actitud primordialmente axiológica. ${ }^{18}$

El vínculo interpersonal no es siempre tan sencillo como en el caso del ejemplo del accidente de trabajo. Una de las características de la relación procesal, verbigracia, es su complejidad. Se dice que es compleja porque no se agota en un solo nexo normativo, sino que supone una larga serie de relaciones de derecho, constitutivas del proceso. Frente al derecho subjetivo que el actor posee de pedir la aplicación del derecho objetivo a un caso concreto, para el esclarecimiento de una situación jurídica incierta o controvertida, encontramos el deber, impuesto a ciertos órganos del Estado, de ejercer la llamada función jurisdiccional. De modo análogo, frente al derecho de defensa del demandado existe la obligación, impuesta al juez, de realizar esa misma función. Entre la demanda y la sentencia descubrimos una serie más o menos complicada de actos, preparatorios del fallo. Pues, como escribe Alberto dos Reis,

a sentença não surge de improviso; o direito processual objectivo não permite que a sentença seja proferida senão depois de praticados certos actos tendentes a preparar a decisão do juiz: a sentença é o termo natural duma seqüēncia de actos processuais realizados pelas partes e pelos funcionários de justiça. Desta maneira o direito de acção ou o direito a sentença desdobra-se numa série de faculdades ou de poderes a que correspondem outras tantas obrigações por parte dos órgãos jurisdicionais; o autor exerce os vários poderes contidos no direito de acção, praticando os actos processuais regulados pelo direito judiciário, desde a petição inicial até ao oferecimento das alegações finais, e provocando a prática de actos correspondentes por parte dos funcionários judiciais. ${ }^{19}$

18 E. García Máynez, Lógica del raciocinio juridico, cap. III, 3.

19 A. Dos Reis, Proceso ordinário e sumário, Coimbra, 1928, I, p. 150. 
Pero, lo mismo que el actor, el demandado tiene el derecho de realizar un conjunto de actos de procedimiento, correlativos de otros tantos deberes del juez o tribunal. Se establece así una compleja trama de vínculos jurídicos que, considerada en su totalidad, aparece ante nosotros como un proceso orientado hacia la declaración oficial del derecho. Mas la aplicación de éste a casos concretos de la experiencia jurídica puede también ser obra de particulares. Ocurre así cuando los últimos - sin acudir a los tribunales- aplican normas jurídicas a casos que realizan los supuestos de tales normas, individualizando, de común acuerdo, las consecuencias de derecho señaladas por la disposición de las mismas normas.

Eduardo García Máynez

Instituto de Investigaciones Filosóficas

Universidad Nacional Autónoma de México 